
and Wrangellia and implications for North America Cordilleran evolution: Lithosphere, doi: 10.1130/L364.1.

\title{
GEOCHRONOLOGICAL METHODS AND RESULTS
}

\section{CA-TIMS at Pacific Centre for Isotopic and Geochemical Research (University of British Columbia)}

This technique has been modified from CA-TIMS procedures outlined in Mundil et al. (2004), Mattinson (2005), and Scoates and Friedman (2008). After rock samples underwent standard mineral separation procedures zircons were handpicked in alcohol. The clearest, crack- and inclusion-free grains were selected, photographed and then annealed in quartz glass crucibles at $900{ }^{\circ} \mathrm{C}$ for $60 \mathrm{~h}$. Annealed grains were transferred into $3.5 \mathrm{~mL}$ PFA screwtop beakers, sub-boiled HF (49-50\% strength, $\sim 500 \mu \mathrm{L})$ and $\mathrm{HNO}_{3}(\sim 14 \mathrm{~N}, \sim 50 \mu \mathrm{L})$ were added and caps were closed finger tight. The beakers were placed in $125 \mathrm{~mL}$ PTFE liners (up to four per liner) and $\sim 2 \mathrm{~mL} \mathrm{HF}$ and $0.2 \mathrm{~mL} \mathrm{HNO}_{3}$ of the same strength as acid within beakers containing samples were added to the liners. The liners, in stainless steel Parr ${ }^{\mathrm{TM}}$ high pressure dissolution devices, were brought up to a maximum of $175^{\circ} \mathrm{C}$ for $8-16 \mathrm{~h}$. Beakers were removed from liners and zircon was separated from leachate. Zircons were rinsed with $>18$ $\mathrm{M} \Omega \cdot \mathrm{cm}$ water and sub-boiled acetone. Then $2 \mathrm{~mL}$ of subboiled $6 \mathrm{~N} \mathrm{HCl}$ was added and beakers were set on a hotplate at $80-130^{\circ} \mathrm{C}$ for $30 \mathrm{~min}$ and again rinsed with water and acetone. Grain masses were estimated from the dimensions (volumes) of grains. Single grains were transferred into clean $300 \mathrm{uL}$ PFA microcapsules (crucibles), and $50 \mu \mathrm{L} 50 \% \mathrm{HF}$ and $5 \mu \mathrm{L} 14$ $\mathrm{N} \mathrm{HNO}_{3}$ were added. Each was spiked with a ${ }^{233-235} \mathrm{U}_{-}^{205} \mathrm{~Pb}$ tracer solution (typically 4-10 mg), capped and again placed in a Parr liner (8-13 microcapsules per liner). HF and nitric acids in a 10:1 ratio, respectively, were added to the liner, which was then placed in Parr high pressure device in oven at $240{ }^{\circ} \mathrm{C}$ for $40 \mathrm{~h}$ and complete dissolution was achieved. The resulting solutions were dried on a hotplate at $130{ }^{\circ} \mathrm{C} ; 50 \mu \mathrm{L} 6 \mathrm{~N} \mathrm{HCl}$ was added to microcapsules and fluorides were dissolved in high pressure Parr devices for $12 \mathrm{~h}$ at $210 \mathrm{C}$. $\mathrm{HCl}$ solutions were transferred into clean $7 \mathrm{~mL}$ PFA beakers and dried with $2 \mu \mathrm{L}$ of $0.5 \mathrm{~N} \mathrm{H}_{3} \mathrm{PO}_{4}$. $\mathrm{Pb}$ and $\mathrm{U}$ for each grain were loaded onto a degassed, zone-refined single Re filaments in $2 \mu \mathrm{L}$ of silicic acid/phosphoric acid emitter (Gerstenberger and Haase, 1997).

Isotopic ratios were measured using a modified single collector VG-54R thermal ionization mass spectrometer equipped with analogue Daly photomultiplier. Measurements were done in peak-switching mode on the Daly detector. Analytical blanks were $0.2 \mathrm{pg}$ for $\mathrm{U}$ and for $\mathrm{Pb}$ in the range of $0.5-2.0 \mathrm{pg}$. U fractionation was determined directly on individual runs using the 233-235U tracer, and $\mathrm{Pb}$ isotopic ratios were corrected for fractionation of 0.23 $\pm 0.05 \%$ /a.m.u. (1 sigma), based on replicate analyses of the NBS-982 Pb reference material and the values recommended by Thirlwall (2000). Uranium was analyzed as $\mathrm{UO}_{2}$ and was corrected for isobaric interference of ${ }^{233} \mathrm{U}^{18} \mathrm{O}{ }^{16} \mathrm{O}$ on ${ }^{235} \mathrm{U}^{16} \mathrm{O}^{16} \mathrm{O}$ with an ${ }^{18} \mathrm{O} /{ }^{16} \mathrm{O}$ of 0.00205 . Data reduction employed the Excel-based program of Schmitz and Schoene (2007) and the U decay constants of Jaffe et al. (1971).

Weighted mean ${ }^{206} \mathrm{~Pb} /{ }^{238} \mathrm{U}$ ages were calculated from three and four equivalent dates, for 08-SI-179 and 08-SI-090, respectively using Isoplot 3.0 (Ludwig, 2003) and are interpreted as being the igneous crystallization age. Error on the weighted mean ${ }^{206} \mathrm{~Pb} /{ }^{238} \mathrm{U}$ dates is the internal error based on analytical uncertainties only; it is given at the $2 \sigma$ confidence interval. This error should be used when comparing these dates with ${ }^{206} \mathrm{~Pb} /{ }^{238} \mathrm{U}$ dates from other laboratories that used the same UBC tracer solution or a tracer solution that was crosscalibrated using EARTHTIME gravimetric standards. When comparing our dates with those derived from laboratories that did not use the same tracer solution or a tracer solution that was not cross-calibrated using EARTHTIME gravimetric standards, a systematic uncertainty in the 
tracer calibration of $0.1 \%$ should be added to the internal errors in quadrature. When comparing our date with those derived from other decay schemes (e.g., ${ }^{40} \mathrm{Ar} /{ }^{39} \mathrm{Ar},{ }^{187} \operatorname{Re}-{ }^{187} \mathrm{Os}$ ), systematic uncertainties in the tracer calibration and ${ }^{238} \mathrm{U}$ decay constant (Jaffey et al., 1971) should be added to the internal error in quadrature

$\mathrm{U}-\mathrm{Pb}$ dates and uncertainties were calculated using the algorithms of Schmitz and Schoene (2007), ${ }^{235} \mathrm{U} /{ }^{205} \mathrm{~Pb}$ of 571.53 and ${ }^{233} \mathrm{U} /{ }^{235} \mathrm{U}$ of 1.026482 for the UBC tracer solution, and $\mathrm{U}$ decay constants of Jaffey et al. (1971). ${ }^{206} \mathrm{~Pb} /{ }^{238} \mathrm{U}$ ratios and dates were corrected for initial ${ }^{230} \mathrm{Th}$ disequilibrium using a Th/U[magma] $=3$ using the algorithms of Crowley et al. (2007), that result in an increase in the ${ }^{206} \mathrm{~Pb} /{ }^{238} \mathrm{U}$ dates of $\sim 0.09 \mathrm{Ma}$.

Four aliquots of the EARTHTIME 100 Ma synthetic solution measured during the course of analytical work for this study used the UBC tracer solution and the same mass spectrometry methods described above. Each aliquot was $45-50 \mathrm{pg}$ of radiogenic $\mathrm{Pb}$, slightly larger than the average analysis measured during this study. The weighted mean ${ }^{206} \mathrm{~Pb} /{ }^{238} \mathrm{U}$ and ${ }^{207} \mathrm{~Pb} /{ }^{235} \mathrm{U}$ dates are $100.03 \pm 0.08 / 0.12$ and $100.03 \pm 0.12 / 0.15 \mathrm{Ma}$, respectively. These dates agree with the known dates determined by analysis of large aliquots measured with the EARTHTIME mixed ${ }^{233} \mathrm{U}_{-}^{235} \mathrm{U}_{-}{ }^{202} \mathrm{~Pb}_{-}{ }^{205} \mathrm{~Pb}$ tracer solution (D. Condon, unpublished data).

\section{U-Pb Geochronology Results}

Four grains from sample 08-SI-179-1 were analyzed, three of which yielded a weighted mean ${ }^{206} \mathrm{~Pb} /{ }^{238} \mathrm{U}$ date of $363.47 \pm 0.94 \mathrm{Ma}(\mathrm{MSWD}=0.13$ ). This is the interpreted igneous crystallization age of the rock. The fourth grain gives older and only marginally concordant results and is interpreted to contain an older, xenocrystic core. Including a systematic uncertainty in the tracer calibration increases the error to $\pm 1.00 \mathrm{Ma}$. Including a systematic uncertainty in the decay constant increases the error to $\pm 1.07 \mathrm{Ma}$.

Four grains from sample 08 -SI-090 were analyzed and yielded a weighted mean ${ }^{206} \mathrm{~Pb} /{ }^{238} \mathrm{U}$ date of $352.84 \pm 0.30 \mathrm{Ma}(\mathrm{MSWD}=0.11)$. This is the interpreted igneous crystallization age of the rock. Including a systematic uncertainty in the tracer calibration increases the error to $\pm 0.45 \mathrm{Ma}$. Including a systematic uncertainty in the decay constant increases the error to $\pm 0.59 \mathrm{Ma}$.

\section{CA-TIMS at Isotope Geology Laboratory at Boise State University}

$\mathrm{U}-\mathrm{Pb}$ dates were obtained by the chemical abrasion isotope dilution thermal ionization mass spectrometry (CA-TIMS) method from analyses composed of single zircon grains . Zircon grains were separated from rocks using standard techniques and mounted in epoxy and polished until the centers of the grains were exposed. Cathodoluminescence (CL) images were obtained with a JEOL JSM-1300 scanning electron microscope and Gatan MiniCL. Zircon was then removed from the epoxy mounts and subjected to a modified version of the chemical abrasion method of Mattinson (2005), reflecting analysis of single grains. Grains were selected for dating based on CL images that appear to lack inherited cores.

Zircon was placed in a muffle furnace at $900{ }^{\circ} \mathrm{C}$ for $60 \mathrm{~h}$ in quartz beakers. Single grains were then transferred to $3 \mathrm{ml}$ Teflon PFA beakers and loaded into $300 \mu \mathrm{l}$ Teflon PFA microcapsules. Fifteen microcapsules were placed in a large-capacity Parr vessel, and the crystals partially dissolved in $120 \mu \mathrm{l}$ of $29 \mathrm{M} \mathrm{HF}$ for $12 \mathrm{~h}$ at $180{ }^{\circ} \mathrm{C}$. The residual grains were returned to $3 \mathrm{ml}$ Teflon PFA beakers and HF was removed. Grains were immersed in $3.5 \mathrm{M}$ $\mathrm{HNO}_{3}$, ultrasonically cleaned for an hour, and fluxed on a hotplate at $80{ }^{\circ} \mathrm{C}$ for an hour. The $\mathrm{HNO}_{3}$ was removed and grains were rinsed twice in ultrapure $\mathrm{H}_{2} \mathrm{O}$ before being reloaded into the same $300 \mu \mathrm{l}$ Teflon PFA microcapsules (rinsed and fluxed in $6 \mathrm{M} \mathrm{HCl}$ during sonication and washing of the grains) and spiked with the Boise State University mixed ${ }^{233} \mathrm{U}_{-}{ }^{235} \mathrm{U}_{-}{ }^{205} \mathrm{~Pb}$ tracer solution. The chemically abraded grains were dissolved in Parr vessels in $120 \mu \mathrm{l}$ of $29 \mathrm{M}$ $\mathrm{HF}$ with a trace of $3.5 \mathrm{M} \mathrm{HNO}_{3}$ at $220^{\circ} \mathrm{C}$ for $48 \mathrm{~h}$, dried to fluorides, and then re-dissolved in 
$6 \mathrm{M} \mathrm{HCl}$ at $180^{\circ} \mathrm{C}$ overnight. $\mathrm{U}$ and $\mathrm{Pb}$ were separated from the zircon matrix using an $\mathrm{HCl}-$ based anion-exchange chromatographic procedure (Krogh, 1973), eluted together and dried with $2 \mu 1$ of $0.05 \mathrm{~N} \mathrm{H}_{3} \mathrm{PO}_{4}$.

$\mathrm{Pb}$ and $\mathrm{U}$ were loaded on a single outgassed $\mathrm{Re}$ filament in $5 \mu \mathrm{l}$ of a silicagel/phosphoric acid mixture (Gerstenberger and Haase, 1997), and $\mathrm{U}$ and $\mathrm{Pb}$ isotopic measurements made on a GV Isoprobe-T multicollector thermal ionization mass spectrometer equipped with an ion-counting Daly detector. $\mathrm{Pb}$ isotopes were measured by peak-jumping all isotopes on the Daly detector for 100-160 cycles, and corrected for $0.18 \pm 0.03 \% /$ a.m.u. (1 sigma) mass fractionation. Transitory isobaric interferences due to high-molecular weight organics, particularly on ${ }^{204} \mathrm{~Pb}$ and ${ }^{207} \mathrm{~Pb}$, disappeared within $\sim 30$ cycles, while ionization efficiency averaged $10^{4} \mathrm{cps} / \mathrm{pg}$ of each $\mathrm{Pb}$ isotope. Linearity (to $\geq 1.4 \times 10^{6} \mathrm{cps}$ ) and the associated deadtime correction of the Daly detector were monitored by repeated analyses of NBS982, and have been constant since installation. Uranium was analyzed as $\mathrm{UO}_{2}{ }^{+}$ions in static Faraday mode on $10^{11} \mathrm{ohm}$ resistors for 200-250 cycles, and corrected for isobaric interference of ${ }^{233} \mathrm{U}^{18} \mathrm{O}{ }^{16} \mathrm{O}$ on ${ }^{235} \mathrm{U}^{16} \mathrm{O}{ }^{16} \mathrm{O}$ with an ${ }^{18} \mathrm{O} /{ }^{16} \mathrm{O}$ of 0.00206 . Ionization efficiency averaged $20 \mathrm{mV} / \mathrm{ng}$ of each $\mathrm{U}$ isotope. $\mathrm{U}$ mass fractionation was corrected using the known ${ }^{233} \mathrm{U} /{ }^{235} \mathrm{U}$ ratio of the ET535 tracer solution.

A weighted mean ${ }^{206} \mathrm{~Pb} /{ }^{238} \mathrm{U}$ date was calculated from six equivalent dates using Isoplot 3.0 (Ludwig, 2003) and is interpreted as being the igneous crystallization age. Error on the weighted mean ${ }^{206} \mathrm{~Pb} /{ }^{238} \mathrm{U}$ dates is the internal error based on analytical uncertainties only, including counting statistics, subtraction of tracer solution, and blank and initial common $\mathrm{Pb}$ subtraction. It is given at the $2 \sigma$ confidence interval. This error should be considered when comparing our date with ${ }^{206} \mathrm{~Pb} /{ }^{238} \mathrm{U}$ dates from other laboratories that used the same Boise State University tracer solution or a tracer solution that was cross-calibrated using EARTHTIME gravimetric standards. When comparing our date with those derived from laboratories that did not use the same tracer solution or a tracer solution that was not cross-calibrated using EARTHTIME gravimetric standards, a systematic uncertainty in the tracer calibration of $0.1 \%$ should be added to the internal errors in quadrature. When comparing our date with those derived from other decay schemes (e.g., ${ }^{40} \mathrm{Ar} /{ }^{39} \mathrm{Ar},{ }^{187} \mathrm{Re}-{ }^{187} \mathrm{Os}$ ), systematic uncertainties in the tracer calibration and ${ }^{238} \mathrm{U}$ decay constant (Jaffey et al., 1971) should be added to the internal error in quadrature.

$\mathrm{U}-\mathrm{Pb}$ dates and uncertainties were calculated using the algorithms of Schmitz and Schoene (2007), ${ }^{235} \mathrm{U} /{ }^{205} \mathrm{~Pb}$ of 77.93 and ${ }^{233} \mathrm{U} /{ }^{235} \mathrm{U}$ of 1.007066 for the Boise State University tracer solution, and $U$ decay constants recommended by Jaffey et al. (1971). ${ }^{206} \mathrm{~Pb} /{ }^{238} \mathrm{U}$ ratios and dates were corrected for initial ${ }^{230} \mathrm{Th}$ disequilibrium using a Th/U[magma] $=3 \pm 0.3$ (1 sigma) using the algorithms of Crowley et al. (2007), resulting in an increase in the ${ }^{206} \mathrm{~Pb} /{ }^{238} \mathrm{U}$ dates of $\sim 0.09 \mathrm{Ma}$. All common $\mathrm{Pb}$ in analyses was attributed to laboratory blank and subtracted based on the measured laboratory $\mathrm{Pb}$ isotopic composition and associated uncertainty. U blanks are difficult to precisely measure, but are estimated at $0.07 \mathrm{pg}$.

Seven aliquots of the EARTHTIME 100 Ma synthetic solution were measured during this experiment using the Boise State University tracer solution and the same mass spectrometry methods described above. Each aliquot was 4-6 pg of radiogenic $\mathrm{Pb}$, slightly smaller than the average analysis measured during the experiment. The weighted mean ${ }^{206} \mathrm{~Pb} /{ }^{238} \mathrm{U}$ and ${ }^{207} \mathrm{~Pb} /{ }^{235} \mathrm{U}$ dates are $100.08 \pm 0.03 / 0.10$ and $100.04 \pm 0.13 / 0.16 \mathrm{Ma}$, respectively. These dates agree with the known dates determined by analysis of large aliquots measured with the EARTHTIME mixed ${ }^{233} \mathrm{U}_{-}{ }^{235} \mathrm{U}_{-}{ }^{202} \mathrm{~Pb}-{ }^{205} \mathrm{~Pb}$ tracer solution (D. Condon, unpublished data).

\section{U-Pb Geochronology Results}

Six analyzed grains from sample 10 -SI-217-1 yielded a weighted mean ${ }^{206} \mathrm{~Pb} /{ }^{238} \mathrm{U}$ date of $363.53 \pm 0.12 \mathrm{Ma}(\mathrm{MSWD}=0.4$ ). This is the interpreted igneous crystallization age. 
Including a systematic uncertainty in the tracer calibration increases the error to $\pm 0.37 \mathrm{Ma}$. Including a systematic uncertainty in the decay constant increases the error to $\pm 0.53 \mathrm{Ma}$.

\section{REFERENCES CITED}

Crowley, J.L., Schoene, B., and Bowring, S.A., 2007, U-Pb dating of zircon in the Bishop Tuff at the millennial scale: Geology, v. 35, p. 1123-1126, doi:10.1130/G24017A.1.

Gerstenberger, H., and Haase, G., 1997, A highly effective emitter substance for mass spectrometric $\mathrm{Pb}$ isotope ratio determinations: Chemical Geology, v. 136, p. 309-312, doi:10.1016/S0009-2541(96)00033-2.

Jaffey, A.H., Flynn, K.F., Glendenin, L.E., Bentley, W.C., and Essling, A.M., 1971, Precision measurements of half-lives and specific activities of ${ }^{235} \mathrm{U}$ and ${ }^{238} \mathrm{U}$ : Physical Review C: Nuclear Physics, v. 4, p. 1889-1906, doi:10.1103/PhysRevC.4.1889.

Krogh, T.E., 1973, A low contamination method for hydrothermal decomposition of zircon and extraction of $\mathrm{U}$ and $\mathrm{Pb}$ for isotopic age determination: Geochimica et Cosmochimica Acta, v. 37, p. 485-494, doi:10.1016/0016-7037(73)90213-5.

Ludwig, K.R., 2003, User's Manual for Isoplot 3.00. Berkeley Geochronology Center: Berkeley, CA, $70 \mathrm{p}$.

Mattinson, J.M., 2005, Zircon U-Pb chemical abrasion ("CA-TIMS") method: combined annealing and multi-step partial dissolution analysis for improved precision and accuracy of zircon ages: Chemical Geology, v. 220, p. 47-66, doi:10.1016/j.chemgeo.2005.03.011.

Mundil, R., Ludwig, K.R., Metcalfe, I., and Renne, P.R., 2004, Age and Timing of the Permian Mass Extinctions: U/Pb Dating of Closed-System Zircons: Science, v. 305, p. 1760-1763, doi:10.1126/science.1101012.

Schmitz, M.D., and Schoene, B., 2007, Derivation of isotope ratios, errors and error correlations for $\mathrm{U}-\mathrm{Pb}$ geochronology using ${ }^{205} \mathrm{~Pb}-{ }^{235} \mathrm{U}-\left({ }^{233} \mathrm{U}\right)$-spiked isotope dilution thermal ionization mass spectrometric data: Geochemistry Geophysics Geosystems, v. 8, G3, p. Q08006, doi:10.1029/2006GC001492.

Scoates, J.S., and Friedman, R.M., 2008, Precise age of the platiniferous Merensky Reef, Bushveld Complex, South Africa, by the U-Pb zircon chemical abrasion ID-TIMS technique: Economic Geology and the Bulletin of the Society of Economic Geologists, v. 103, p. 465-471, doi:10.2113/gsecongeo.103.3.465.

Thirlwall, M.F., 2000, Inter-laboratory and other errors in $\mathrm{Pb}$ isotope analyses investigated using a 207Pb-204Pb double spike: Chemical Geology, v. 163, p. 299-322, doi:10.1016/S0009-2541(99)00135-7. 